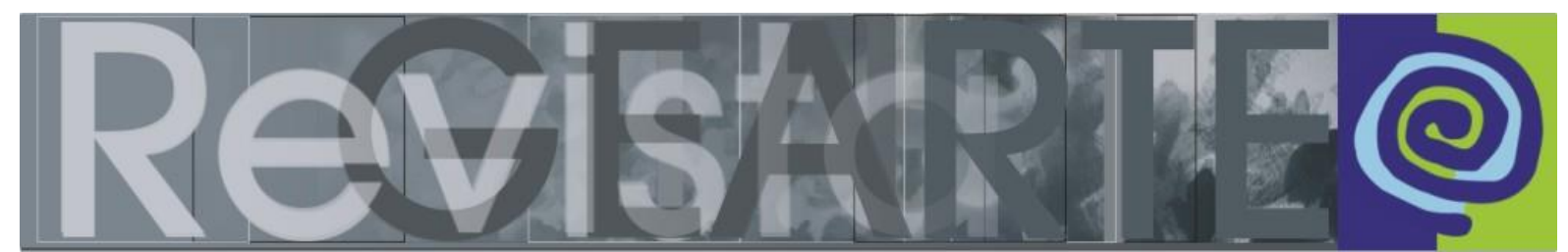

ISSN 2357-9854 | e-ISSN 2596-3198 (online)

\title{
O corpo e o movimento na formação em pedagogia: \\ o papel das histórias de vida e das memórias corporais como um campo de experimentação e reflexividade
}

\author{
Ana Paula Abrahamian de Souza \\ (Universidade Federal Rural de Pernambuco - UFRPE, Recife/PE, Brasil)
}

\begin{abstract}
RESUMO - O corpo e o movimento na formação em pedagogia: o papel das histórias de vida e das memórias corporais como um campo de experimentação e reflexividade - Neste artigo trago algumas materialidades vivenciadas por mim como docente de um Curso de Licenciatura em Pedagogia em uma universidade pública no nordeste do Brasil, para problematizar o silenciamento do corpo e do movimento nos currículos universitários. A minha hipótese é que a universidade brasileira tem formado educadores/as com poucos repertórios para atuação com a linguagem corporal na e para as Infâncias, que tendem a perpetuar discursos cristalizados em modos particulares assentados no racionalismo cartesiano que tomam como premissa o corpo homogêneo, único, docilizado e higienizado. Nos limites deste texto irei partilhar algumas experiências estético-pedagógicas tomando como eixo as memórias e as histórias de vida dos/das discentes, e os possíveis rebatimentos que a reflexão sobre as corporeidades pode trazer à práxis do/a futuro/a professor/a.
\end{abstract}

PALAVRAS-CHAVE

Formação de Professores. Arte na Pedagogia. Corporeidade.

\begin{abstract}
The body and movement in pedagogy training: the role of life stories and body memories as a field of experimentation and reflexivity - This article brings some materialities experienced by a lecturer of a Licentiate Degree in Pedagogy at a public university in northeastern Brazil, to discuss the silencing of the body and movement in university curricula. The study's hypothesis is that the Brazilian university has trained educators with few repertoires to work with body language in and for childhood, who tend to perpetuate discourses crystallized in particular ways based on Cartesian rationalism that take as a premise the homogeneous, unique, docile and sanitized body. Within its limits this text shares some aesthetic-pedagogical experiences around the axis of the memories, life stories of the students and the possible repercussions that the reflection on corporeality can bring to the praxis of the future teacher.
\end{abstract}

\section{KEYWORDS}

Teacher training. Art in Pedagogy. Corporeality.

RESUMEN - El cuerpo y el movimiento en la formación pedagógica: el papel de las historias de vida y las memorias corporales como campo de experimentación y reflexividad - En este artículo traigo algunas materialidades vivenciadas por mí como docente de un Curso de Licenciatura en Pedagogía en una universidad pública en el nordeste de Brasil, para problematizar el silenciamiento del cuerpo y del movimiento en los currículos universitarios. Mi hipótesis es que la universidad brasileña tiene formando educadores/as con pocos repertorios para actuación con el lenguaje corporal en la y para las Infancias, que tienden a perpetuar discursos cristalizados en modos particulares asentados en el racionalismo cartesiano que toman como premisa el cuerpo homogéneo, único, docilizado e higienizado. En los límites de este texto voy a compartir algunas experiencias estético-pedagógicas tomando como eje las memorias y las historias de vida de los/las dicentes, y los posibles rebatimientos que la reflexión sobre las corporeidades puede traer a la práxis del/ de la futuro/a profesor/a.

PALABRAS CLAVE

Formación de Profesores. Arte en la Pedagogía. Corporeidad.

SOUZA, Ana Paula Abrahamian de. O corpo e o movimento na formação em pedagogia: o papel das 303

histórias de vida e das memórias corporais como um campo de experimentação e reflexividade.

Revista GEARTE, Porto Alegre, v. 8, n. 2, p. 303-321, maio/ago. 2021.

http://dx.doi.org/10.22456/2357-9854.117504 


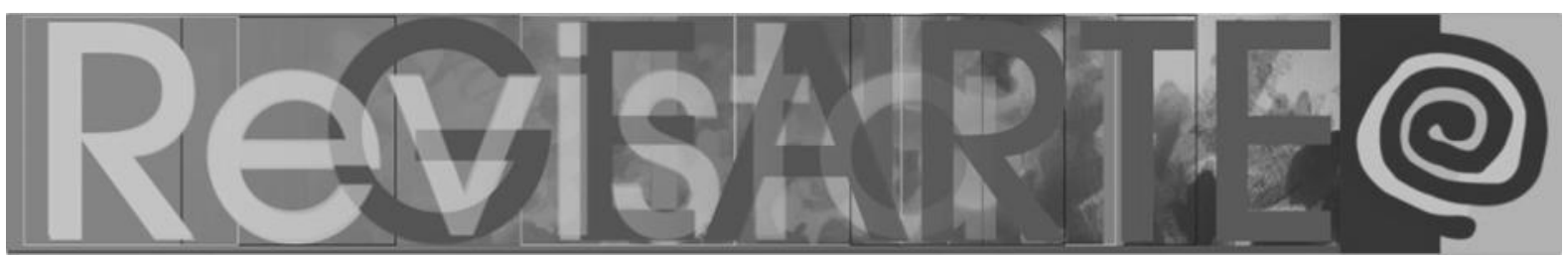

"Professora, você pode listar atividades corporais que podemos realizar com as crianças nas vivências do estágio supervisionado?"

"Professora, ajuda... as crianças não param quietas um minuto..."

"Ana, as crianças só querem dançar Passinho e Brega [...]. Estou desesperado."

Gostaria de iniciar este texto com frases recorrentes que tenho escutado de estudantes do curso de Licenciatura em Pedagogia desde o início das minhas atividades na Universidade Federal Rural de Pernambuco (UFRPE), nas quais tenho trabalhado com o corpo enquanto linguagem e com a Dança como componente curricular no campo da arte/educação. Ávidos por "dar conta" das demandas dos "pequenos corpos agitados e que não param" e das especificidades das infâncias nos espaços escolarizados, os/as estudantes chegam a minhas disciplinas e projetos de extensão demandando por danças prontas, atividades motoras de todas as ordens, como se a produção de um "cardápio" de atividades fosse "salvar", pelo menos, alguns minutos da rotina nas salas de educação infantil. "Professora, é porque saio da escola e parece que um trator passou por cima de mim." Esse é o cenário que me atravessa todos os semestres letivos e que gostaria de compartilhar com os/as leitores/as.

O que tenho observado com os/as estudantes é uma problemática instaurada nos Projetos Pedagógicos dos Cursos de Licenciatura no que se refere ao silenciamento do corpo e do movimento nos currículos universitários. A minha hipótese é que a universidade brasileira tem formado educadores/as com poucos repertórios para atuação com a linguagem corporal na e para as Infâncias, que tendem a perpetuar discursos cristalizados em modos particulares assentados no racionalismo cartesiano que tomam como premissa o corpo homogêneo, único e docilizado e higienizado.

Neste texto, irei argumentar a necessidade de reflexão sobre a formação docente, em que o/a professor/a não seja apenas competente tecnicamente, ligado 


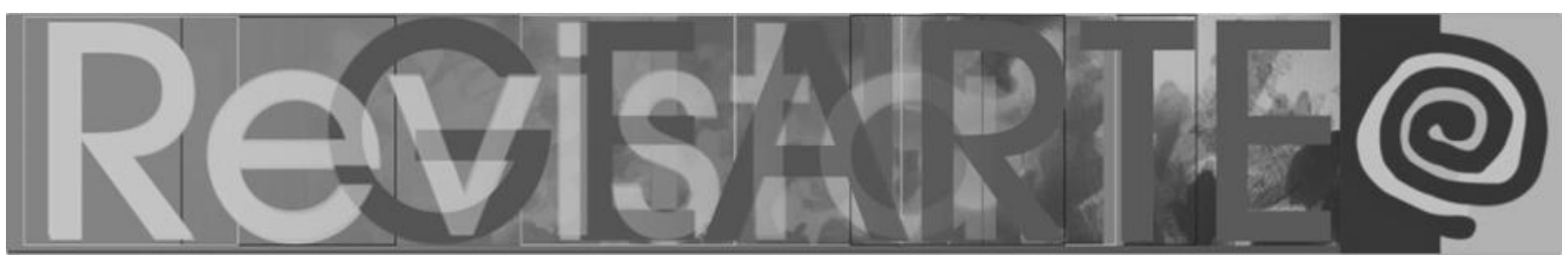

simplesmente à aplicação e ao manejo de um conjunto de técnicas e métodos prescritivos, mas numa perspectiva crítica em que o/a docente seja reflexivo/a, propositivo/a e revolucionário/a em seu fazer. Para os cursos de Pedagogia, essa reflexão torna-se premissa, posto que a própria contextualização desse campo do conhecimento traz uma compreensão bastante limitada sobre o corpo, sobre o movimento e a sua importância no processo de desenvolvimento nas/das Infâncias.

É a partir dessas questões que gostaria de partilhar algumas experiências enquanto docente, tomando como eixo de trabalho as memórias e as histórias de vida dos/das discentes e os possíveis rebatimentos que a corporeidade pode trazer à práxis do/a futuro/a professor/a, que se sobrepõe e cria interfaces com a educação dos sujeitos em sua integralidade. Quero dizer com isso que esse texto é uma tentativa dada a pensar que as histórias de vida, ao nos marcarem, também nos formam ao provocarem novas elaborações dos nossos corpos, dos corpos dos/das outro/as e dos nossos corpos no mundo.

\section{Movimentos iniciais: a problemática da inserção da corporeidade nos currículos dos cursos de formação de professores no Brasil}

A problematização sobre a inserção do corpo e do movimento nos currículos dos cursos de formação de professores nas universidades brasileiras é uma história recente, que ganha relevância com um conjunto de discussões políticas e conceituais (MARQUES, 1996; STRAZZACAPPA, 2006). No entanto, como foi observado em outra publicação ${ }^{1}$ (SOUZA; FERREIRA, 2015), apesar do avanço das discussões teóricas e legais nos cursos de Licenciatura em Pedagogia, percebe-se que as questões marcadas pelo corpo e pelo movimento possuem pouca visibilidade nos currículos, apesar de representarem uma das linguagens que deveria ser trabalhada em sua integralidade. O que se observa, atualmente, é que a universidade brasileira tem formado professores/as com poucos repertórios, os quais tendem a perpetuar práticas cristalizadas das dancinhas escolares, com 


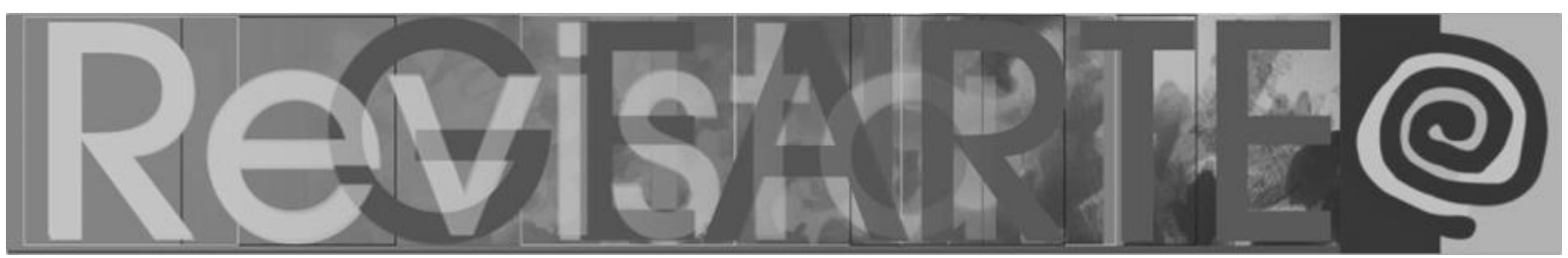

seus movimentos estereotipados e repetitivos que são produzidas nas diferentes comemorações durante todo o ano letivo, que se inicia no Carnaval e finaliza no Natal.

É nesse contexto que se apresentam os desafios e os questionamentos que este texto tem por objetivo problematizar: como promover ações sobre o corpo e o movimento no curso de Licenciatura em Pedagogia a partir de um diálogo críticoreflexivo? Como propor novas perspectivas de/para a formação de professores que promova vivências artísticas e estéticas a partir das diferentes corporeidades dos/das participantes?

Nesse aspecto, apresento algumas experiências realizadas na UFRPE, tomando as memórias e as histórias de vida como eixo fundante de ressignificação de algumas práticas corporais a partir de processos em que a reflexividade dos próprios corpos é tomada como premissa. Irei dialogar com as ideias trazida por Jussara Setenta (2008, p. 30), compreendendo que os corpos são permeados por um sentido político, ou seja, agem no mundo a partir de uma determinada "coleção de informação".

Assim, este artigo está sendo caracterizado por movimentos de uma dança que estou imaginando. Esta ideia de movimento traz também um caráter não estático, dinâmico, em constantes ressignificações. No Movimento Um, trago a reflexão sobre o Ensino da Dança na contemporaneidade, filiando-me às reflexões da Dança/Educação. No Movimento Dois, procuro relatar as experiências vividas e partilhadas no Curso de Licenciatura em Pedagogia, em ações de ensino e de extensão, desde o ano de 2014. Gostaria de tomar como foco o trabalho com as memórias e com as histórias de vida e os processos de reflexividade potencializadores de significações outras, que desmitificam o discurso dos corpos ideais para o trânsito com a perspectiva dos corpos-ideias. Para finalizar essa "dança", procurei retomar os objetivos anunciados no texto, percebendo o potencial dos espaços formativos da universidade como capazes de propor vivências entre 


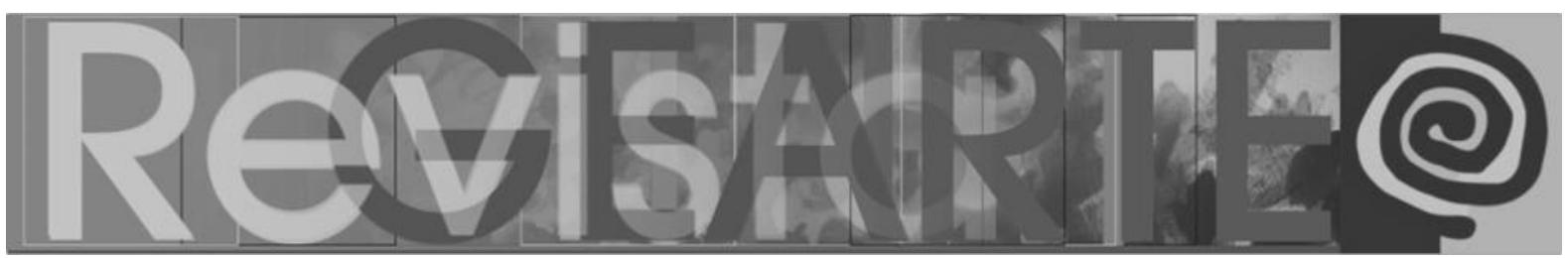

teoria e prática numa dinâmica dialógica e compromissada com a formação de professores no Brasil.

\section{Movimento Um: O que é mesmo Dança/Educação?}

A observação do mundo das Artes evidencia um movimento questionador sobre o próprio estatuto de existência delas, como observa Marques (1996, p. 17):

A arte mudou. Na verdade, mudou o conceito de arte. Depois que Duchamp levou o mictório para o museu (os ready-made); que Andy Warhol pintou latas de sopa Campbell's; que Jonh Cage escreveu 4'33; que Steve Paxton criou seus Walking Pieces, não se pode mais dizer que existe a Obra de Arte, feita para ser contemplada à distância por uma platéia selecionada.

A dança foi atingida por esses rumos estatutários, constituindo-se por peças que desafiam a existência de códigos preestabelecidos, como o da dança clássica ou acadêmica, como também o da dança moderna, procurando-se, cada vez mais, outras maneiras de ser e fazer dança, ora privilegiando o corpo, o contexto ou o conteúdo, ora incorporando e interagindo com novas formas de expressão artística, surgidas na manipulação ilimitada das tecnologias como o vídeo, a holografia, a comunicação computadorizada, etc. (BANES, 1980), sendo definida por Gehres (2008, p. 14)

Como um texto cujos significados são negociados a cada vivência/experimentação, a dança é, bem como outras formas de significação sociocultural, processo, e não produto, de criação/recriação do homem com seu mundo [...]. Assim entendida, uma dança é, em outras palavras, uma maneira de existência humana a qual não pode ser aprisionada nos limites de uma descrição, demonstração ou apresentação.

No entanto, apesar da mudança conceitual sobre o estatuto da dança na contemporaneidade, o seu ensino continua arraigado práticas estereotipadas e sedimentadas em ideais de beleza que são transpostos para os corpos das crianças acriticamente. Cito como exemplo, os eventos festivos tão comuns nas escolas que tem a dança como "instrumento" para a culminância de projetos e datas comemorativas. São nesses momentos que podemos observar as crianças 


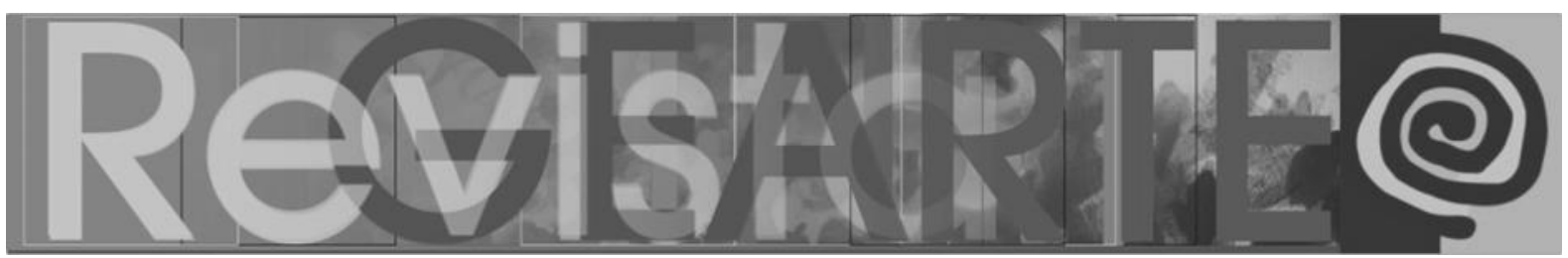

vestidas de coelhinhos, soldados e matutos juninos, celebrando festas descontextualizadas para deleite dos pais e de familiares que, incansavelmente, registram tudo para a posteridade.

As décadas de 1980, 1990 e 2000 foram marcadas por um conjunto de discussões políticas e conceituais sobre o ensino de Arte consideradas eixos desencadeadores de mudanças. No tocante à legislação, foram estruturadas as discussões e a proposição da Lei de Diretrizes e Bases da Educação Nacional, em sua última alteração, dada pela Lei n. 13.415, de fevereiro de 2017 , na qual o ensino da arte foi apresentado como "especialmente em suas expressões regionais, constituirá componente curricular obrigatório da educação básica" (BRASIL, 2017)².

Derivou dessas premissas a elaboração dos Parâmetros Curriculares Nacionais (PCNs), nos quais a arte se apresenta como área de conhecimento que requer espaço e constância, como todas as áreas do currículo escolar (BRASIL, 1998), abrangendo, no Ensino Fundamental, as linguagens artísticas: Artes Visuais, Dança, Música e Teatro. Ao considerar tais aspectos, os PCNs de Arte trouxeram consigo uma compreensão da dança mais abrangente do que aquela que se restringe a uma animação para as festas escolares, a um instrumento facilitador do aprendizado de outras disciplinas ou uma possibilidade de extravasamento das emoções (SOUZA 2009).

Vale também destacar o Referencial Curricular Nacional para a Educação Infantil (RCNEI), publicado no ano de 1998, como parte integrante de uma conjunção de fatores em prol do atendimento às crianças de zero a seis anos reivindicados pela sociedade civil e pelos órgãos governamentais reconhecidos pela Constituição Federal de 1988, pelo Estatuto da Criança e do Adolescente, de 1990, reafirmado pela LDBN 9.394/96. Ao ser considerado um divisor nas políticas públicas para a Educação Infantil no Brasil, ressalto a preocupação na garantia do desenvolvimento das múltiplas linguagens infantis, tendo como principais objetivos 


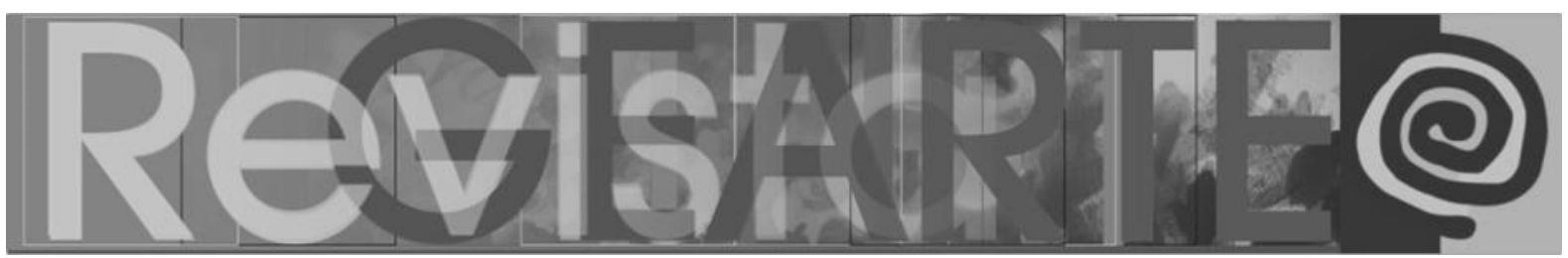

auxiliar o professor na realização do trabalho educativo junto a crianças pequenas; incorporar às atividades educativas os cuidados essenciais das crianças e suas brincadeiras, visando ao desenvolvimento integral das identidades infantis (SOUZA, 2015). Nesse sentido, o conhecimento das potencialidades corporais (BRASIL, 1998) é tomado como um dos atributos para a educação dos sujeitos infantis, juntamente com os conhecimentos das potencialidades afetivas, emocionais, estéticas e éticas, na perspectiva de contribuir para a formação integral (BRASIL, 1998).

Outro marco legal importante foi a Resolução CNP/CP, n. 01, de 15 de maio de 2006, que institui as Diretrizes Curriculares Nacionais para o Curso de Graduação em Pedagogia, que apontam um avanço quando definem "a aplicação, em práticas educativas, de conhecimentos de processos de desenvolvimento de crianças, adolescentes, jovens e adultos em suas diferentes dimensões (BRASIL, 2006), evidenciando a importância do trabalho e das experimentações corporais na formação de professores para atuarem com a Educação Infantil.

Entre os anos de 2014 e 2018, marcados em torno do documento preliminar da BNCC proposto pela Secretaria de Educação Básica do Ministério da Educação (SEB/MEC), foram salientados nas etapas da Educação Infantil e do Ensino Fundamental "competências básicas" para a Educação Básica:

[...] 3. Valorizar e fruir as diversas manifestações artísticas e culturais, das locais às mundiais, e também participar de práticas diversificadas da produção artístico-cultural e 4. Utilizar diferentes linguagens - verbal (oral ou visual-motora, como Libras, e escrita), corporal, visual, sonora e digital -, bem como conhecimentos das linguagens artística, matemática e científica, para se expressar e partilhar informações, experiências, ideias e sentimentos em diferentes contextos e produzir sentidos que levem ao entendimento mútuo (BRASIL, 2017, p. 9).

Quanto às questões do campo teórico e metodológico, desde o início da década de 1990, observa-se um conjunto de práticas apoiado nos trabalhos de Rudolf Laban (1998) e seus discípulos (PRESTON-DUNLOP, 1998; STINSON, 1998, 1995) que, aqui no Brasil, foi encabeçado pela professora Isabel de Azevedo 


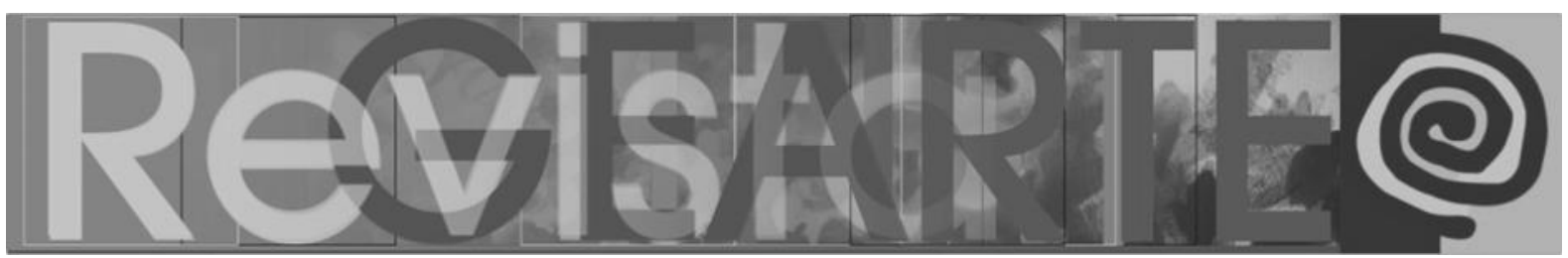

Marques, podendo ser entendida como um conjunto de diretrizes políticas e pedagógicas que busca garantir a dança, o corpo e o movimento no ensino para todos os alunos e alunas - independentemente de qualquer forma de diferenciação étnica, social, sexual, política e cultural - e o preparo de todos para a vida numa sociedade que trabalhe com as diferenças.

O alicerce da proposta está fincado nas redes de relações mutáveis, múltiplas e indeterminadas traçadas em sala de aula entre a arte da dança, o ensino e a sociedade e que podem articular passado, presente e futuro por meio de corpos pensantes, críticos e historicizados. Este tripé arte - ensino - sociedade serve de base, fundamentação e justificativa para a proposta metodológica que Isabel Marques vem desenvolvendo desde 1992, como assessora de Educação Artística/Dança na rede municipal de ensino de São Paulo, nomeada em 1996, a Dança no contexto. A autora propõe que o trabalho com o contexto dos alunos seja o ponto de partida e aquilo a ser construído, trabalhado, desvelado, problematizado, transformado e desconstruído em uma ação educativa transformadora na área de dança (MARQUES, 1996).

O contexto dos alunos é entendido num sentido mais abrangente: um contexto palpável que mantém relações múltiplas com a "gigantesca realidade imaginária" do que é percebido e sentido (MARQUES, 1996, p. 93). Ele é tomado como um interlocutor da prática educativa, ressaltando que a escolha do tema a ser trabalhado pelos alunos não deve estar baseada, apenas, no interesse motivacional e, sim, na possibilidade de eles exporem significados que elucidam a nossa sociedade, o que aproxima da ideia de problematização. Esse contexto é a base para as formulações dos textos, subtextos e contextos da própria dança.

Os subtextos são os aspectos coreológicos, ou seja, elementos estruturais da dança, e seus elementos socioafetivo-culturais. A relação inicial entre o contexto/subtextos elucida quais são os textos mais apropriados a serem trabalhados com os alunos. Os textos da dança são tratados como todas aquelas 


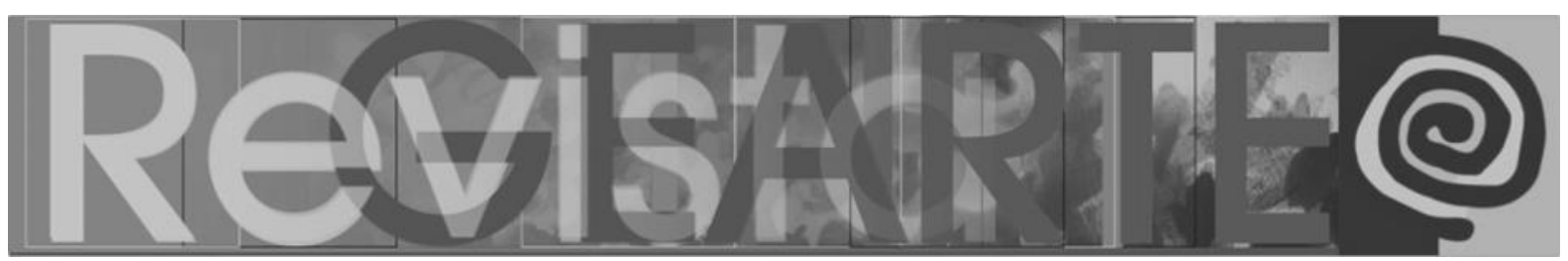

proposições que trabalham o mundo da dança ou seus processos, indo do universo dos repertórios ao reconhecimento da importância das composições e das improvisações. No contexto da própria dança, temos elementos históricos, culturais e sociais da dança, tais como o trato com a história, música, antropologia, estética, apreciação e crítica, etc. Tais elementos podem ser sintetizados como mostra a Figura 1.

Figura 1 - Sistematização da Abordagem Dança no Contexto (MARQUES, 1996)

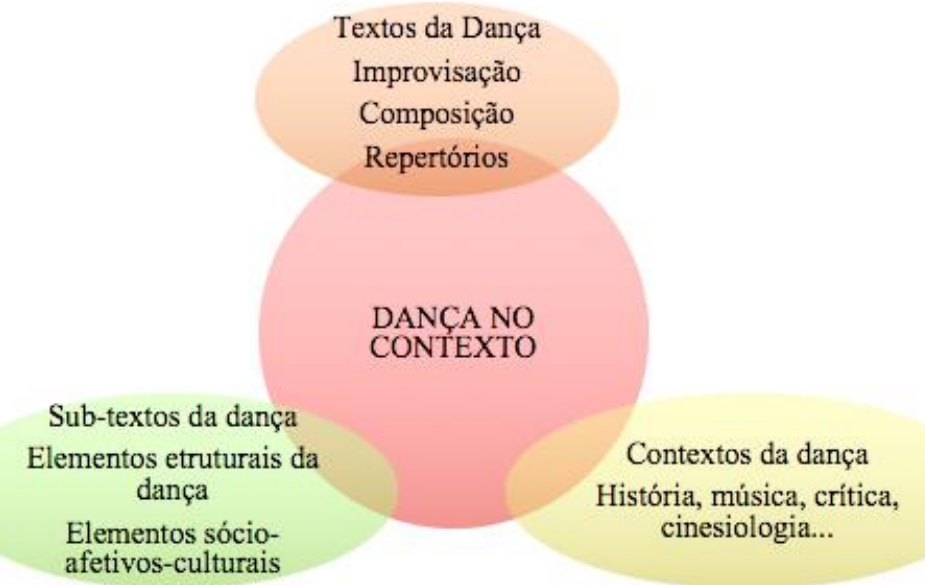

Fonte: Acervo da autora, 2015.

Assim, dentro dos pressupostos acima mencionados, o diálogo com os/as estudantes do Curso de Pedagogia que a Dança/Educação mostra-se enquanto uma prática que se propõe: participativa - por meio do estímulo à experimentação e à criação artísticas -; crítica - à medida que leva os/as alunos e alunas a fazerem uma leitura crítica da obra de arte e de seu próprio fazer artístico -; individualizada - por tomar cada aluno e aluna nas suas singularidades -; e contextualizante - a partir da análise e da compreensão do momento histórico no qual a abra de arte se encontra inserida e na permanente comparação entre o seu próprio fazer artístico e a realidade na qual se vive. A partir desses pressupostos, gostaria de trazer à cena as histórias de vida e a memória como eixo integrante para pensarmos a corporeidade de cada estudante e os possíveis rebatimentos para a reflexividade da prática pedagógica na formação de professores/as. 


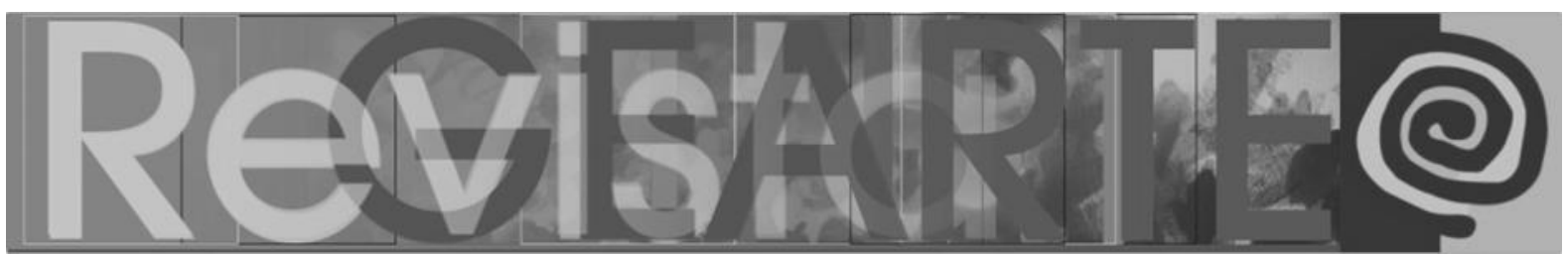

\title{
Movimento Dois: promovendo o debate acerca do Ensino da Dança na contemporaneidade - as memórias e as histórias de vida como eixo de reflexão
}

\begin{abstract}
Hoje estava me recordando o quão maravilhosas eram aquelas aulas que tínhamos no final de cada ano, eram realizadas muitas brincadeiras, com música e dança. Eu fiquei me perguntando: por que passávamos o ano inteiro sentados e enfileirados realizando atividades repetitivas o tempo todo? Eu sei que foram importantes as atividades que realizávamos no nosso caderno, porém elas sozinhas não eram capazes de nos preparar para um mundo tão dinâmico e que exige de nós movimento). (Trecho do caderno de memórias de D., estudante do Curso de Pedagogia, da disciplina Linguagem Corporal e Educação Infantil).
\end{abstract}

Tomo aqui de empréstimo um trecho do caderno de memórias ${ }^{3}$ de um estudante do Curso de Pedagogia para exemplificar a importância do trânsito com as histórias de vida ${ }^{4}$ para a reflexão acerca da corporeidade de cada estudante e os rebatimentos para seu processo formativo. Entendo, como Catani (2005, p. 32), que "as escritas autobiográficas que testemunham as relações pessoais com a escola, podem ser úteis como fonte para a elaboração da história da educação" ao levarmos em consideração os sentimentos, os diferentes significados e as representações das memórias, as histórias e as relações sociais com os seus processos de socialização escolar.

Assim, as histórias de vida e as memórias vividas pelos corpos de cada estudante são tomadas enquanto perspectiva de formação e de autoformação, por buscar a ampliação do campo epistemológico, do panorama histórico a partir dos percursos de vida na formação de professores/as.

Quando invocamos a memória, sabemos que ela é algo que não se fixa apenas no campo subjetivo, já que toda vivência, ainda que singular e auto-referente, situa-se também num contexto histórico e cultural. A memória é uma experiência histórica indissociável das experiências peculiares de cada indivíduo e de cada cultura (SOUZA, 2007, p. 63).

O que quero dizer com isso? Observo no dia a dia da sala de aula, nas experiências que tenho com os/as estudantes a importância dos seus corpos no 


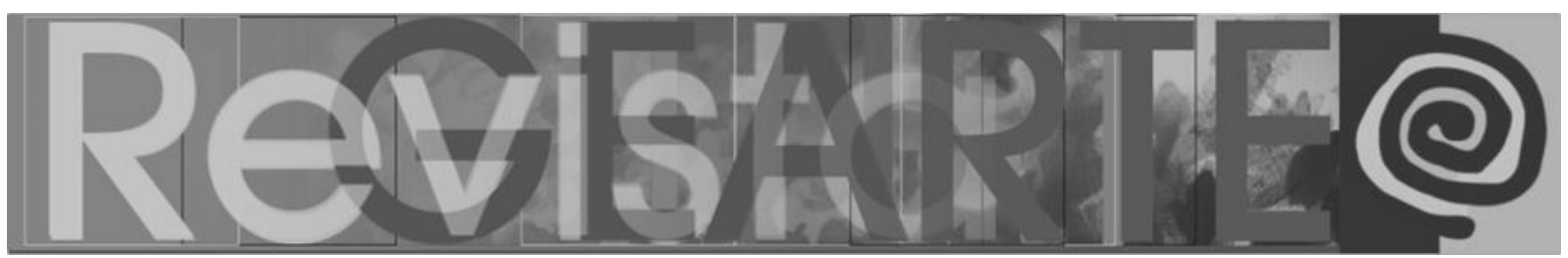

seu papel de intérprete e a importância de chamarmos a memória para a cena, ou como nos provoca Souza (2007, p. 63),

[...] A lembrança remete o sujeito a observar-se numa dimensão genealógica, como um processo de recuperação do eu, e a memória narrativa, como virada significante, marca um olhar sobre si em diferentes tempos e espaços, os quais se articulam com as lembranças e as possibilidades de narrar experiências.

Algumas questões são lançadas para reflexão: "Que corpo? Você já parou para pensar como você se sente no seu próprio corpo? Que memórias do seu corpo na infância? E o corpo no seu processo de escolarização? Brincadeiras? Danças? Movimento? O que você poderia narrar sobre o seu corpo, a sua história nos seus processos educativos? E os seus futuros alunos e alunas? O que vocês observam no Estágio Supervisionado Obrigatório nas salas de Educação Infantil?”. Essas e outras perguntas vão permeando as experiências corporais que vão se entrecruzando com leituras obrigatórias das disciplinas e das ações de extensão. É dessa forma que vamos rememorando antigos cenários para abrir novos espaços de reflexão sobre a corporeidade de cada um e de cada uma. Vamos (re)aprendendo a nos perceber, perceber o/a outro/a, o espaço em volta e dentro de nós mesmos/as.

[...] o corpo fala, o corpo cria, o corpo pensa. Estivemos dizendo todo o tempo aqui que o corpo traz uma história, uma espécie de memória que está impregnada nos músculos, nos tendões, nos órgãos, no padrão de respiração. Memória afetiva dos tempos de infância, memória muscular do desenvolvimento motor nos primeiros anos de vida, e também memória de cada tombo, cada salto, cada cambalhota, cada dança [...] (VIANNA; CASTILHO, 2002, p. 25). 


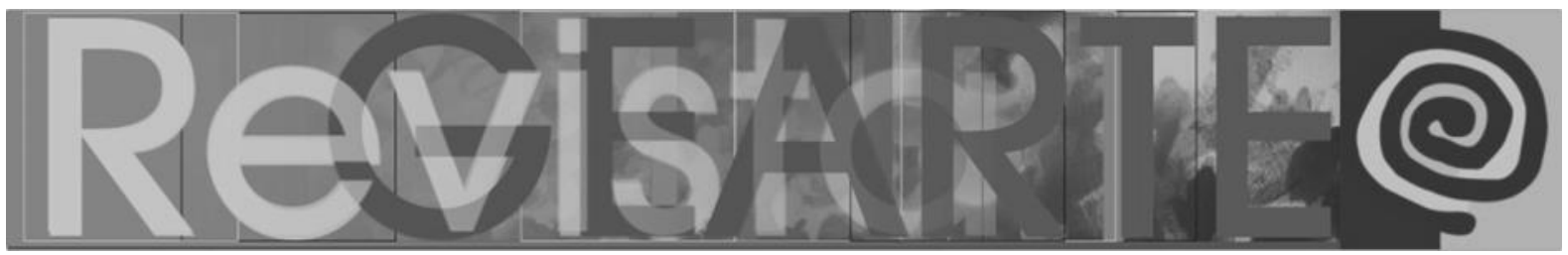

Figura 2 - Trabalho com o grupo de discentes acerca de suas memórias com o corpo e as atividades corporais na escola

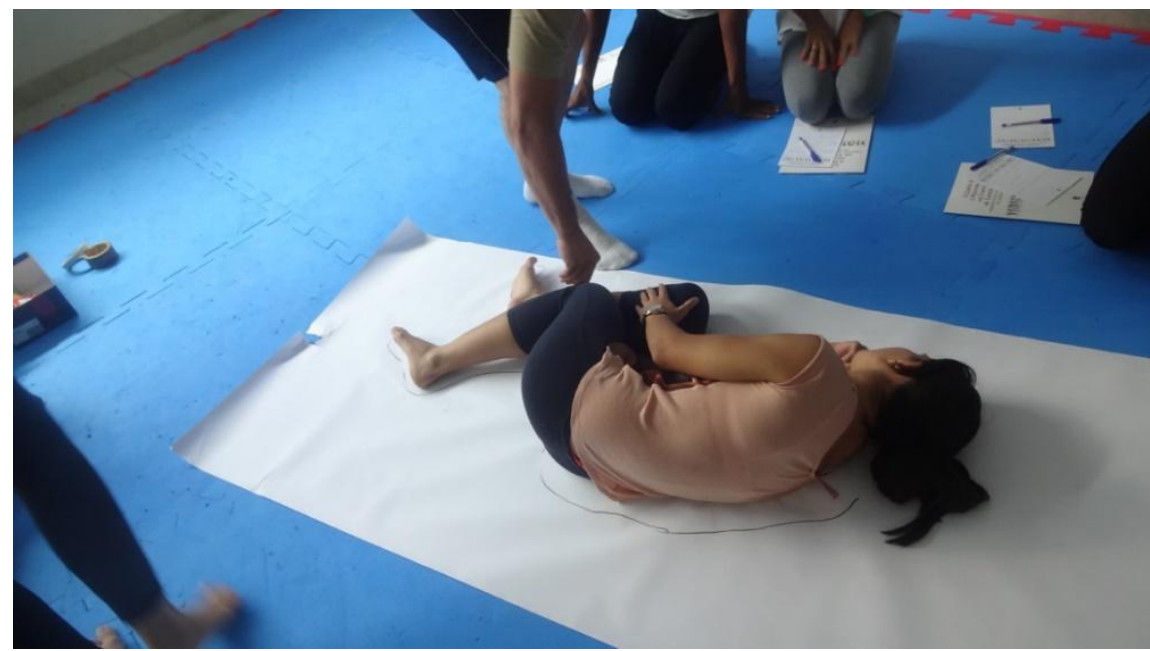

Fonte: Acervo da autora, 2014.

Figura 3 - Trabalho com o grupo de discentes acerca de suas memórias com o corpo e as atividades corporais na escola

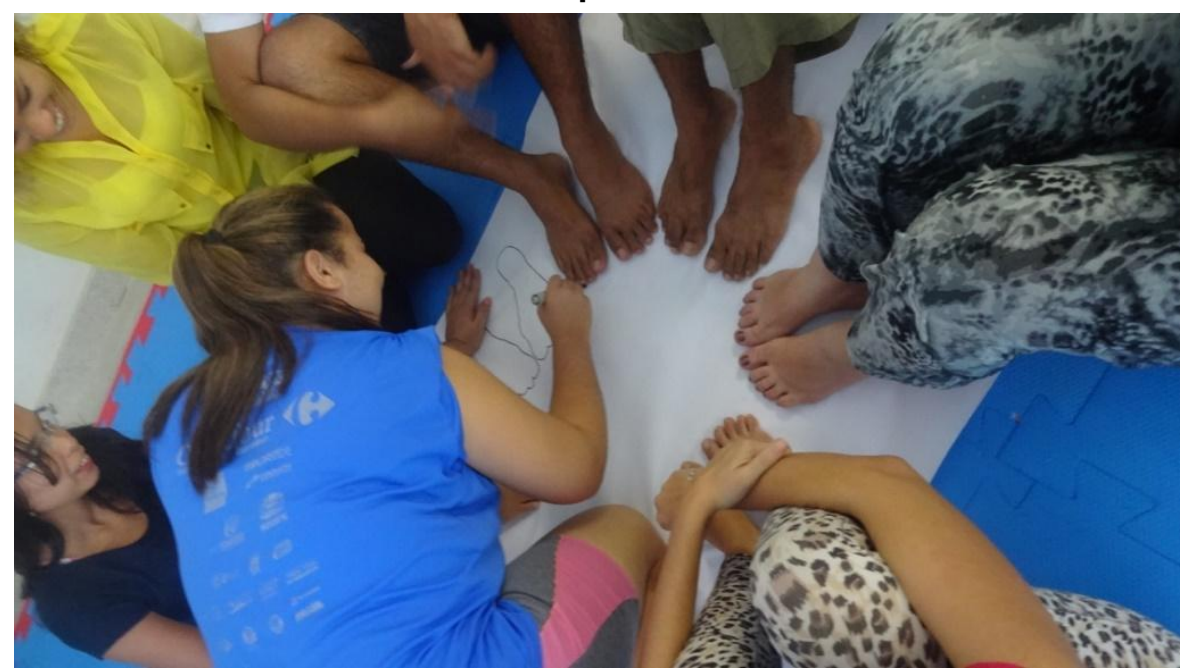

Fonte: Acervo da autora, 2014. histórias de vida e das memórias corporais como um campo de experimentação e reflexividade. Revista GEARTE, Porto Alegre, v. 8, n. 2, p. 303-321, maio/ago. 2021.

Disponível em: http://seer.ufrgs.br/gearte 


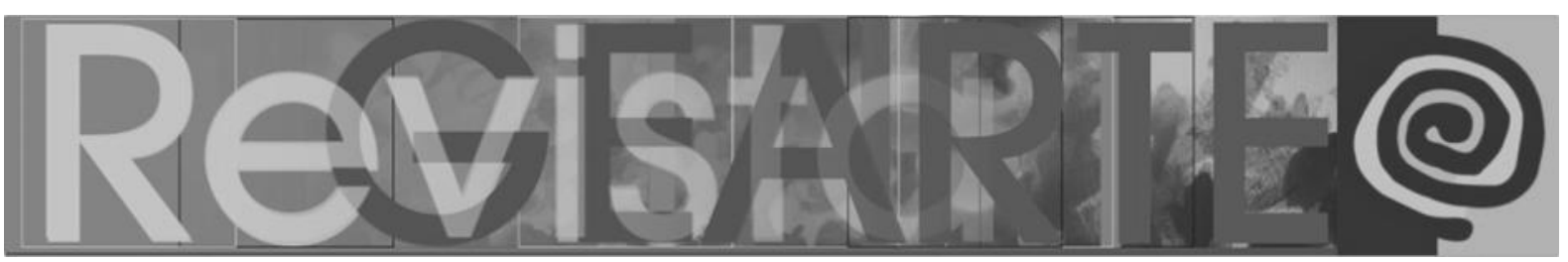

Figura 4 - Trabalho com o grupo de discentes acerca de suas memórias com o corpo e as atividades corporais na escola

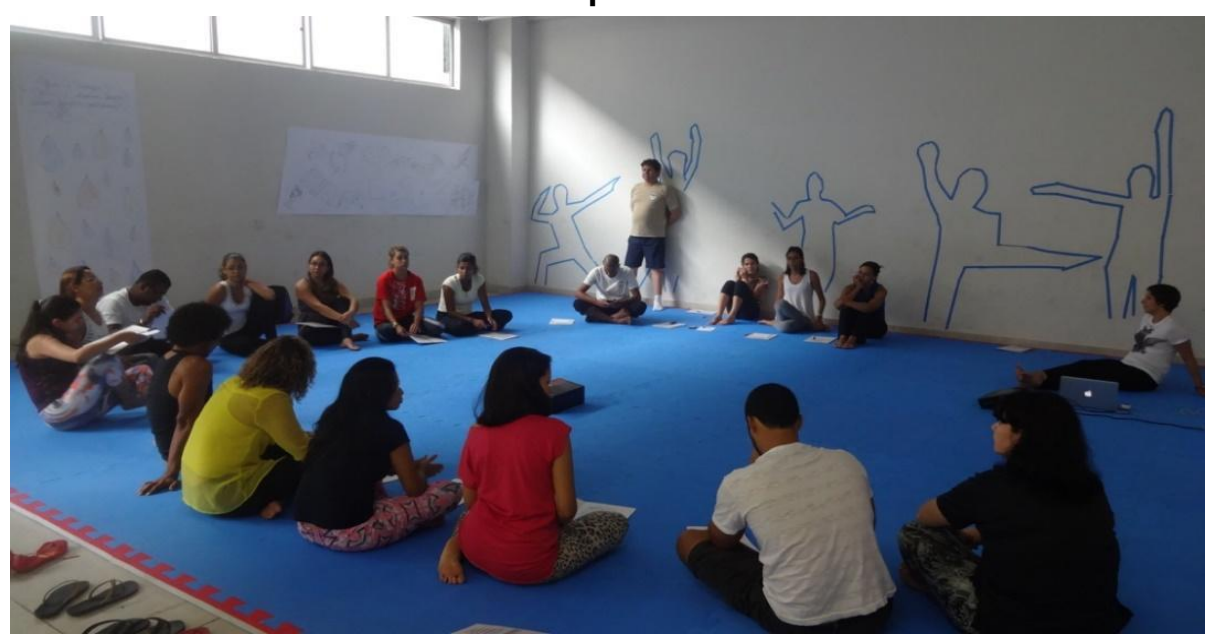

Fonte: Acervo da autora, 2014.

O que tenho percebido ao trabalhar com as memórias e as histórias de vida é a possibilidade do encontro do eu pessoal, que comunica suas experiências corporais e, ao mesmo tempo, a escuta das experiências dos/as colegas é transformada em um exercício de produção de conhecimento e de formação. Essa rememoração é importante, como nos diz Larrosa (1999):

[...] para contarmos o que somos talvez não tenhamos outra possibilidade se não percorrermos de novo as ruínas de nossa biblioteca, para aí tentar reconhecer as palavras que falem por nós. [...] Que podemos cada uma de nós fazer sem transformar nossa inquietude numa história? [...] não será talvez a forma sempre provisória e a ponto de desmoronar que damos ao trabalho infinito de distrair, de consolar ou de acalmar com histórias pessoais aquilo que nos inquieta? (LARROSA, 2010, p. 7).

É assim, dando novos significados aos seus corpos, que os/as estudantes vão se apropriando dos conhecimentos advindos de diferentes campos de saberes e vão anunciando novas possibilidades de trabalho com o corpo, com o movimento e com a dança na Educação Infantil, sugerindo que as experiências, ao nos marcarem, também nos formam, provocando novas elaborações. Entendo ser necessária a reflexão sobre a formação docente em que o professor não seja apenas competente tecnicamente, ligado simplesmente à aplicação e ao manejo de um conjunto de técnicas e métodos prescritivos, mas numa perspectiva crítica em que o docente seja um sujeito reflexivo, propositivo e revolucionário em seu 


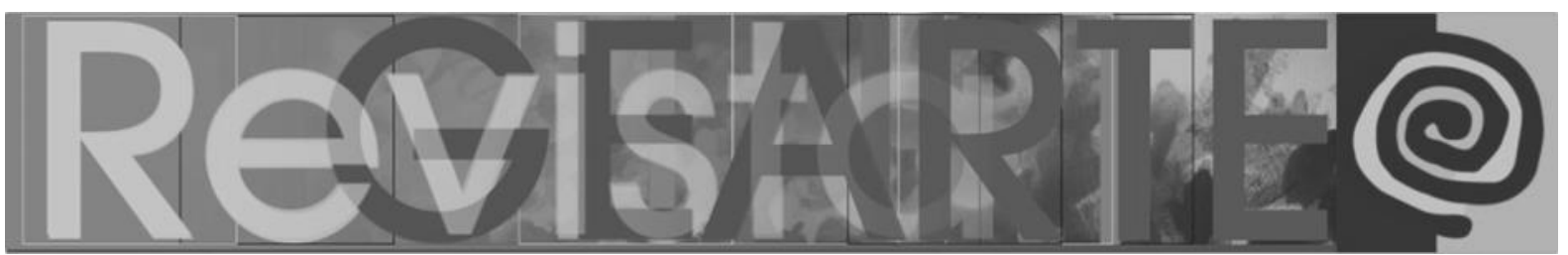

fazer (TARDIF, 2002; GIROUX, 1997; SHÖN, 2000). Para a formação do professor, essa reflexão torna-se premissa, posto que a própria contextualização dessa área do conhecimento nos espaços da educação formal e não formal traz uma compreensão bastante limitada do conceito de corpo, de movimento e da Dança enquanto um campo de conhecimento.

Figura 5 - Trabalho com o grupo de discentes acerca de suas memórias com o corpo e as atividades corporais na escola

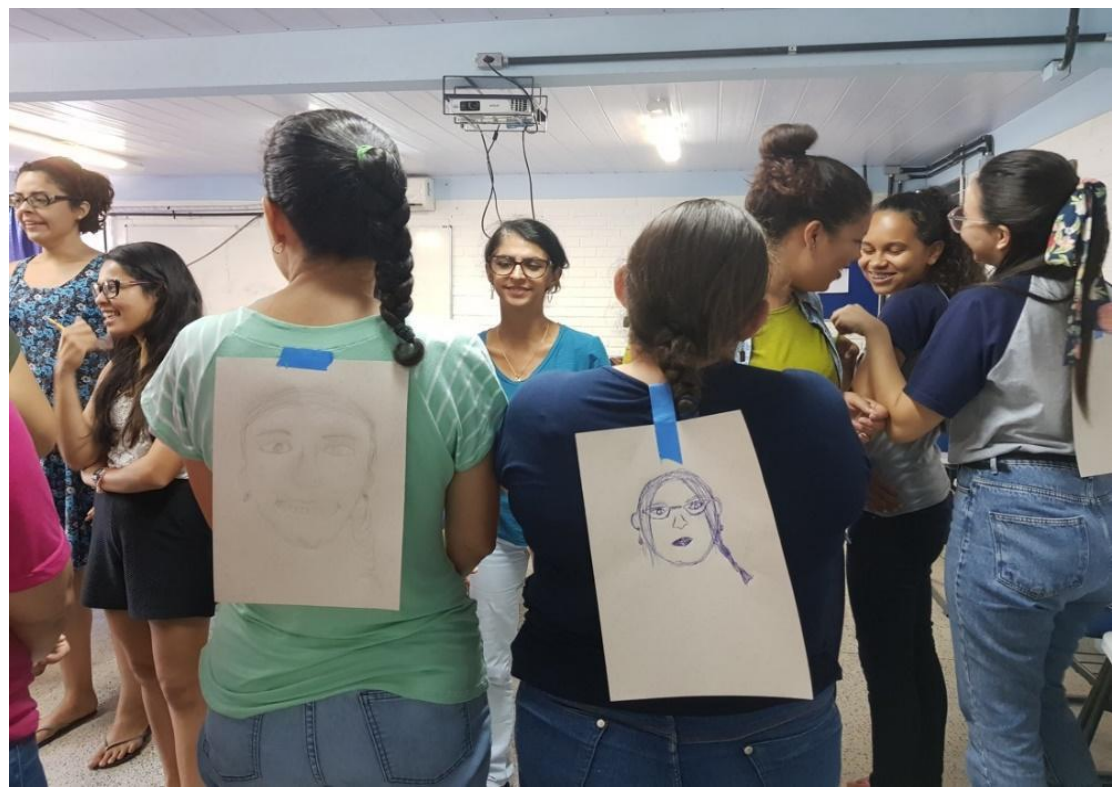

Fonte: Acervo da autora, 2014.

Figura 6 - Trabalho com o grupo de discentes acerca de suas memórias com o corpo e as atividades corporais na escola

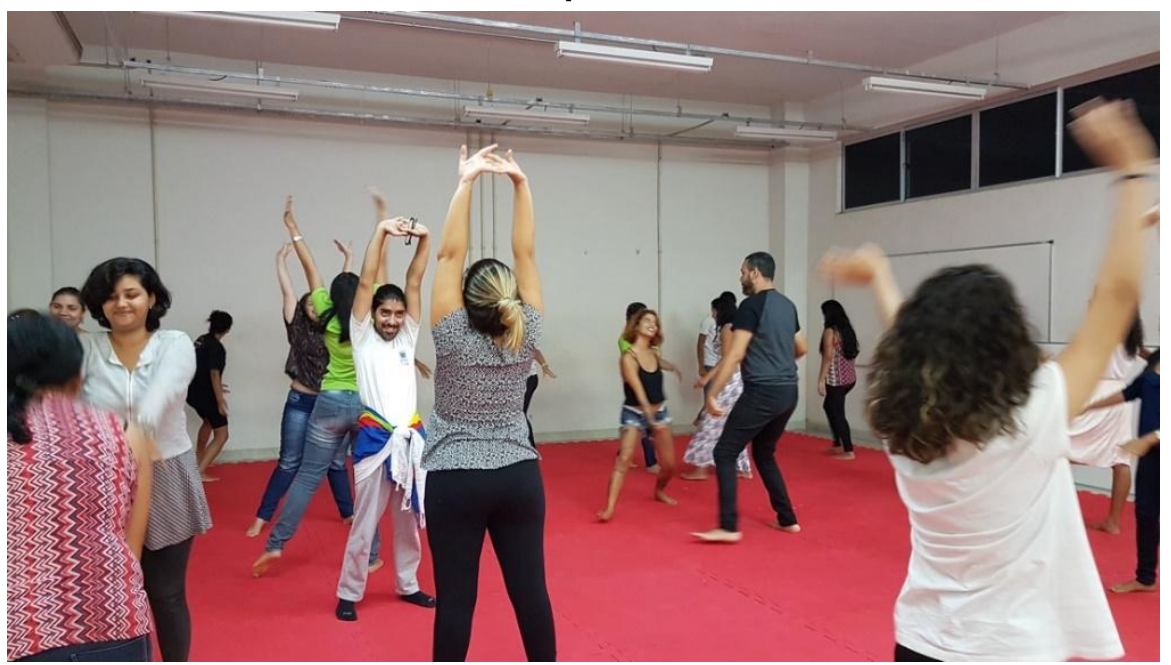

Fonte: Acervo da autora, 2018.

SOUZA, Ana Paula Abrahamian de. O corpo e o movimento na formação em pedagogia: o papel das histórias de vida e das memórias corporais como um campo de experimentação e reflexividade.

Revista GEARTE, Porto Alegre, v. 8, n. 2, p. 303-321, maio/ago. 2021.

Disponível em: http://seer.ufrgs.br/gearte 


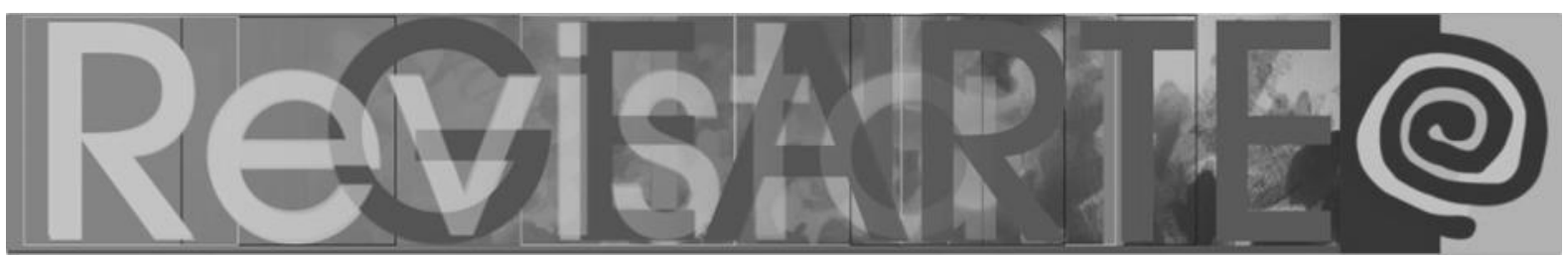

\section{Retomando a questão da Formação de Professores nos Cursos de Licenciatura em Pedagogia, para finalizar}

Retomando a questão inicial que está no cerne deste artigo, relatar algumas experiências vivenciadas por um grupo de estudantes a partir das memórias e das histórias de vida e as possibilidades de reflexão acerca da corporeidade, o que posso ressaltar é que a proposta é um caminho sem volta na proposição de trabalhos interdisciplinares, contextualizantes e provocadores que possam perpassar não somente a ressignificação do próprio estatuto do ensino na contemporaneidade, mas também trazer a reflexão sobre a formação dos/das professores/professoras nos cursos de Pedagogia. Nesse caminho, a tríade compartilhada ensino/pesquisa/extensão pode oxigenar a produção de propostas que proporcionem o trabalho com a corporeidade de cada indivíduo, atribuindo importância para a reflexão da prática escolarizada desse campo de conhecimento na Educação Infantil.

Para mim, trabalhar nessa perspectiva é também mergulhar nos meus mundos vividos como artista, pesquisadora e pedagoga. Acima de tudo, é me disponibilizar a trilhar caminhos investigativos intensos, na descoberta de novas proposições teórico-metodológicas, que me instigam, ao olhar para as memórias dos/das meus alunos/as, olhar para mim mesma, para o corpo que fui, para a docente que sou e para o que estou disponível a aprender, o que me possibilita pensar o meu exercício docente a partir da exposição de novos modos de organizar, escolher, articular e disponibilizar diferentes informações. Como nos fala Perbart (2011, p. 23):

Produzir o novo é inventar novos desejos e novas crenças, novas associações e novas formas de cooperação. Todos e qualquer um inventam, na densidade social da cidade, na conversa, nos costumes, no lazer [...]. A invenção não é prerrogativa dos grandes gênios, nem monopólio da indústria ou da ciência, ela é potência do homem comum. Cada variação, por minúscula que seja, ao propagar-se e ser imitada, torna-se quantidade social, e assim pode ensejar outras invenções e novas imitações, novas associações e novas formas de cooperação. Nessa economia afetiva, a subjetividade não é efeito ou superestrutura etérea, mas força viva, quantidade social, potência psíquica e política. 


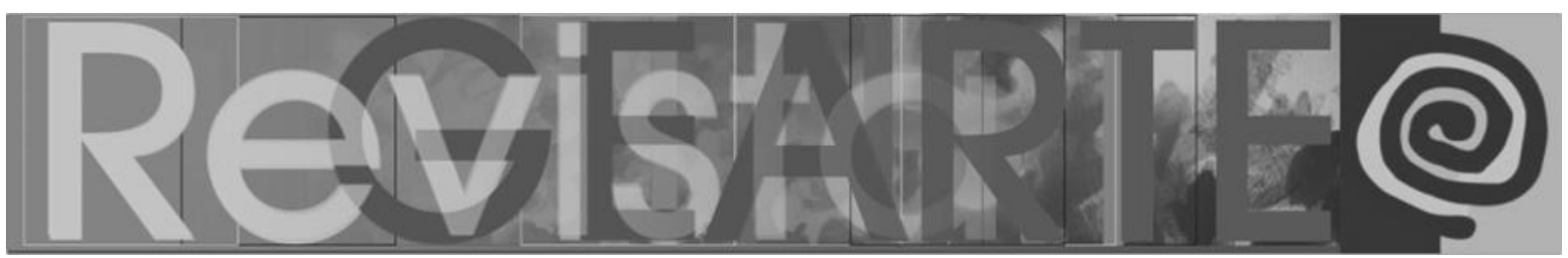

Acredito, assim, na necessidade de reflexões mais aprofundadas sobre 0 corpo e o movimento no espaço da universidade: é uma problemática que diz respeito aos possíveis rebatimentos que a corporeidade pode trazer à práxis do/a professor/a, que se sobrepõe e cria interfaces com a educação do homem em sua integralidade. No momento em que vivemos, em que a Arte tem sido frequentemente censurada e que a "ideologia de gênero" busca definir uma normatividade reguladora, em que o corpo é tomado como um campo de discursividades regido pelo pecado, precisamos produzir novas formas de existir implicados política e esteticamente.

Reitero, para finalizar, a necessidade de pensarmos sobre a educação do/para o corpo que se respalde tanto em sua afirmação como dimensão somática quanto em potência e energia. Nesse viés, educar não passaria pela doutrinação ou pela normatização de gestos, mas pela proposição de experimentá-los a partir de lugares desconhecidos. Aproximando essa ideia com a passagem foucaultiana em que o autor, metaforicamente, usa a imagem do navio como uma heterotopia por excelência ${ }^{5}$, podemos pensar a educação do corpo como heterotopia, na qual o "barqueiro-educador" possa levar o aluno a viajar por lugares outros que não comportem mapas precisos, mas sim cartografias aproximadas de lugares incertos. Uma educação heterotópica que não se conforme com a criação e a reprodução das subjetividades identitárias, mas que promova a produção de processos de subjetivação com resistência aos poderes que reinam nos espaços microfísicos e que se instalam nos corpos. Nesse sentido, a educação para o corpo heterotópico estaria alicerçada no cultivo da estética da existência no âmbito educativo na possibilidade de construção desses corpos-resistência... heterotopias corporais... corpos fora do lugar que transitam por entre as redes discursivas de normatizações e controle. 


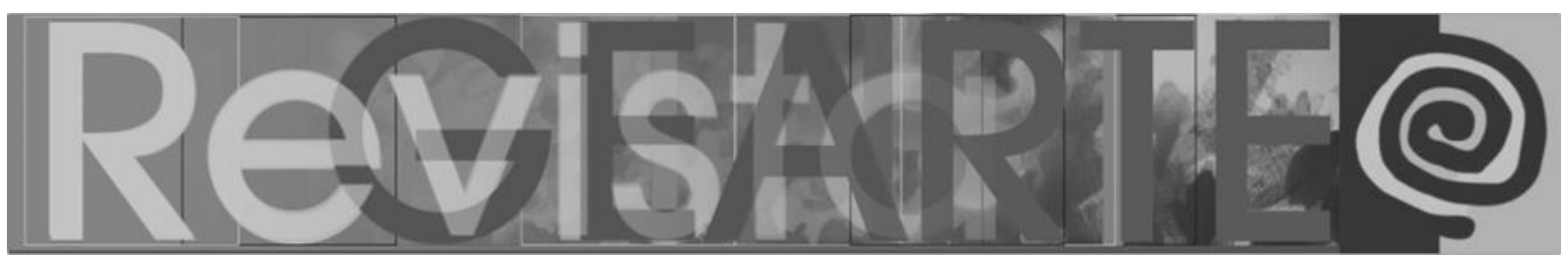

\section{Notas}

1 A publicação a que me refiro fez parte de uma das pesquisas empreendidas pelo Grupo de Pesquisa Arte na Pedagogia - GPAP. Juntamente com Mirza Ferreira produzirmos um artigo intitulado Um Olhar sobre o ensino da Dança nos cursos de Pedagogia.

2 A Lei 13.278/2016 altera a LDBN 9.394/96, Art. 1 o O § 6 o do art. 26 da Lei no 9.394, de 20 de dezembro de 1996, passa a vigorar com a seguinte redação: $\S 60$ As artes visuais, a dança, a música e o teatro são as linguagens que constituirão o componente curricular de que trata o $\S$ 20 deste artigo.

3 O caderno de memórias é uma das estratégias pedagógicas de registro que utilizo tanto nas disciplinas obrigatórias quanto nos projetos de extensão sobre o corpo, o movimento e a Dança enquanto linguagem artística. Ele é produzido em vários formatos, à critério dos/das discentes: um caderno físico, a produção de um blog, falas gravadas ou qualquer suporte que possa dar a ver algumas memórias.

4 Pineau (2006, p. 41) observa a polissemia de terminologias e afirma que "a flutuação terminológica em torno das histórias e relatos de vida, biografias e autobiografias é indicativa da flutuação do sentido atribuído a essas tentativas de expressão da temporalidade vivida pessoalmente"

5 "[...] e se considerarmos que o barco, o grande barco do século XIX, é um pedaço de espaço flutuante, lugar sem lugar, com vida própria, fechado em si, livre em certo sentido, mas fatalmente ligado ao infinito do mar e que, de porto em porto, de zona em zona, de costa em costa, vai até as colônias procurar o que de mais precioso elas escondem naqueles jardins orientais que evocávamos há pouco, compreenderemos porque o barco foi, para a nossa civilização - pelo menos desde o século XVI - ao mesmo tempo, o maior instrumento econômico e nossa maior reserva de imaginação. O navio é a heterotopia por excelência. Civilizações sem barcos são como as crianças cujos pais não tivessem uma grande cama na qual pudessem brincar; seus sonhos então desvanecem, a espionagem substitui a aventura, e a truculência dos policiais, a beleza ensolarada dos corsários" (FOUCAULT, 2013, p. 30).

\section{Referências}

BANES, Sally. Terpsicore in sneakers. Boston: Houghton Mifflin, 1980.

BRASIL. Lei de Diretrizes e Bases da Educação Nacional. Ministério da Educação e do Desporto, Secretaria de Educação Fundamental, Ministério da Educação e do Desporto, Brasília, DF: MEC; SEF, 1996.

BRASIL. Ministério da Educação. Base Nacional Comum Curricular - BNCC, versão aprovada pelo CNE, novembro de 2017. Brasília, DF: Ministério da Educação, 2017. Disponível em: http://basenacionalcomum.mec.gov.br/wpcontent/uploads/2018/02/bncc-20dez-site.pdf.

Acesso em: 1 mar. 2018.

BRASIL. Ministério da Educação e do Desporto. Secretaria de Educação Fundamental. Referencial curricular nacional para a educação infantil. Ministério da Educação e do Desporto, Secretaria de Educação Fundamental. Brasília, DF: MEC; SEF, 1998. v. 1-3.

CATANI, Denice Bárbara. As leituras da própria vida e a escrita de experiências de forma. Educação e Contemporaneidade, Salvador, v. 14, n. 24, p. 31-40, jul./dez. 2005.

FOUCAULT, Michel. O corpo utópico, as heterotopias. São Paulo: N-1 Edições, 2013.

GEHRES, Adriana Farias. Corpo-Dança-Educação na contemporaneidade ou da construção de corpos fractais. Lisboa: Instituto Piaget, 2008.

SOUZA, Ana Paula Abrahamian de. O corpo e o movimento na formação em pedagogia: o papel das

319 histórias de vida e das memórias corporais como um campo de experimentação e reflexividade.

Revista GEARTE, Porto Alegre, v. 8, n. 2, p. 303-321, maio/ago. 2021.

Disponível em: http://seer.ufrgs.br/gearte 


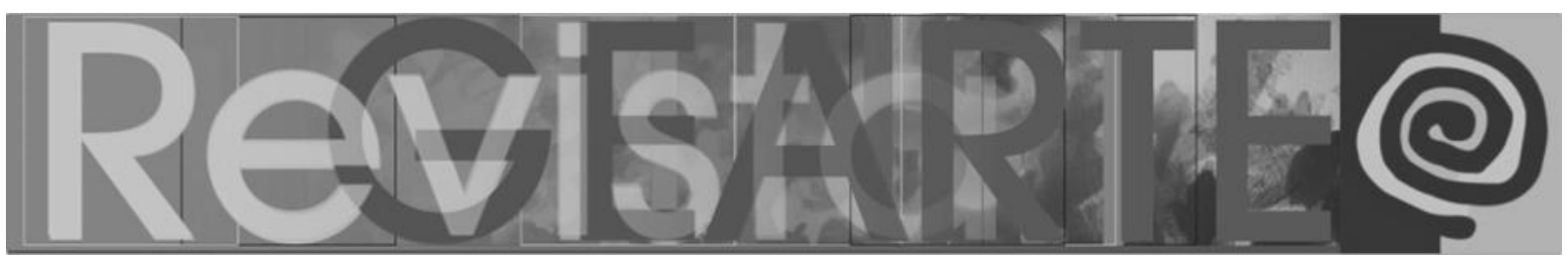

GIROUX, Henry. Os professores como intelectuais: rumo a uma pedagogia crítica da aprendizagem. Porto Alegre: Artes Médicas, 1997.

LABAN, Rudolf. Dança Educativa Moderna. São Paulo: Ícone, 1998.

LARROSA, Jorge. Pedagogia Profana: danças, piruetas e mascaradas. Belo Horizonte: Autêntica, 2010.

MARQUES, Isabel de Azevedo. A Dança no contexto: Uma Proposta para educação contemporânea. 1996. Tese (Doutorado em Educação) - Faculdade de Educação, Universidade de São Paulo, São Paulo, 1996.

MARQUES, Isabel de Azevedo. Dançando na Escola. São Paulo: Cortez, 2003.

MARQUES, Isabel de Azevedo. Ensino de dança hoje: textos e contextos. São Paulo: Cortez, 2001.

PERBART, Peter Pál. Vida Capital: ensaios de biopolítica. São Paulo: lluminuras, 2011.

PRESTON-DUNLOP, Valery. A handbook for dance in education. London: Longman, 1998.

SETENTA, Jussara Sobreira. O faze-dizer do corpo: dança e performatividade. Salvador: EDUFBA, 2008.

SHÖN, Donald. Educando o profissional reflexivo: um novo design para o ensino e para a aprendizagem. Porto Alegre: Artmed, 2000.

SOUZA, Ana Paula Abrahamian. Pesquisas acadêmicas sobre o Ensino da Dança no Brasil: um olhar sobre o banco de teses CAPES. In: CONGRESSO LATINOAMERICANO E CARIBENHO DE ARTE E EDUCAÇÃO, 2009. Anais [...]. Belo Horizonte: UFMG, 2009.

SOUZA, Ana Paula Abrahamian. Redes discursivas sobre os corpos infantis: a pedagogia cultural das danças midiatizadas como região de constituição de subjetividades. 2015. Tese (Doutorado em Educação) - Faculdade de Educação, Universidade Federal de Pernambuco, Recife, 2015.

SOUZA, Ana Paula Abrahamian; FERREIRA, Mirza. Um olhar sobre o ensino da dança nos cursos de Pedagogia. Trama Interdisciplinar, São Paulo, v. 6, n. 2, p. 130-144, 2015.

SOUZA, Elizeu Clementino. (Auto)biografia, histórias de vida e práticas de formação. In: NASCIMENTO, Antônio Dias; HETKOWSKI, Tânia Maria (org.). Memória e formação de professores. Salvador: EDUFBA, 2007.

STINSON, Susan. Seeking a feminist pedagogy for children's dance. In: SHAPIRO, Sherry. Dance, Power and difference: Critical and feminist perspectives on dance education. Champaign: Human Kinetics, 1998.

STINSON, Susan. Uma pedagogia feminista para dança da criança. Pro-posições, Campinas, v. 6 , n. 3, p. 77-89, 1995.

STRAZZACAPPA, Márcia. Entre a arte e a docência: a formação do artista da dança. Campinas: Papirus, 2006.

TARDIF, Maurice. Saberes docentes e formação profissional. Petrópolis, RJ: Vozes, 2002.

VIANNA, Angel, CASTILHO, Jacyan. Percebendo o corpo. In: GARCIA, Regina Leite. O corpo que fala dentro e fora da escola. Rio de Janeiro: DP\&A, 2002.

\section{Ana Paula Abrahamian de Souza}

Professora do Departamento de Educação e do Programa de Pós-Graduação em Educação, Culturas e Identidades da Universidade Federal Rural de Pernambuco. Graduação em Pedagogia, mestre e doutora pela Universidade Federal de Pernambuco. Especialização em Ensino da Dança. Líder do Grupo de Pesquisa em Estudos Culturais e Arte/Educação (GPECAE/UFRPE).

SOUZA, Ana Paula Abrahamian de. O corpo e o movimento na formação em pedagogia: o papel das 320 histórias de vida e das memórias corporais como um campo de experimentação e reflexividade.

Revista GEARTE, Porto Alegre, v. 8, n. 2, p. 303-321, maio/ago. 2021.

Disponível em: http://seer.ufrgs.br/gearte 


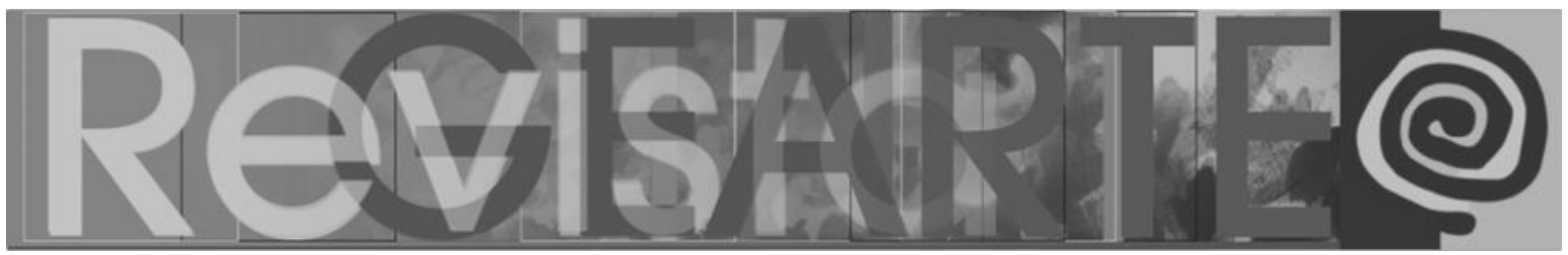

ORCID: https://orcid.org/0000-0002-4321-3458

E-mail: apabrahamian@hotmail.com

Currículo: http://lattes.cnpq.br/5944309643014109

Recebido em 21 de fevereiro de 2021

Aceito em 25 de abril de 2021 histórias de vida e das memórias corporais como um campo de experimentação e reflexividade.

Revista GEARTE, Porto Alegre, v. 8, n. 2, p. 303-321, maio/ago. 2021.

Disponível em: http://seer.ufrgs.br/gearte 